\title{
Saberes e fazeres da gastronomia tradicional: um estudo sobre as características histórico-culturais aplicadas a produção do "Doce de Espécie" no município de Alcântara/MA
}

\author{
Knowledge and practices traditional cuisine: a study of the historical and cultural characteristics applied to \\ production of "Sweet Species" in the Municipality of Alcântara / MA
}

\section{Linda Maria Rodrigues}

Universidade Federal do Maranhão - UFMA - São Luís - Maranhão - Brasil

\section{Elaine Cristina Silva Fernandes}

Universidade Federal do Maranhão - UFMA - São Luís - Maranhão - Brasil

\section{Luana Isthael Carvalho Silva}

Universidade Federal do Maranhão - UFMA - São Luís - Maranhão - Brasil

\begin{abstract}
Resumo: A pesquisa apresenta os estudos e análises dos saberes e fazeres tradicionais aplicados na produção do "doce de espécie" do município de Alcântara/MA. O presente trabalho foi resultado de estudos realizados no Grupo de Estudo "Identidades Culturais da Gastronomia Maranhense" - UFMA, e teve como objetivo compreender os saberes e fazeres gastronômicos que envolvem a produção do Doce de Espécie. Analisar o conhecimento tradicional através da influência dos Açores na preparação do doce. Conhecer a relação do Doce de Espécie com a Festa do Divino realizada anualmente no município de Alcântara/MA. A metodologia utilizada com intuito de alcançar os objetivos propostos se deu através de pesquisa exploratória e descritiva com abordagem qualitativa e coleta de dados por meio de entrevista não estruturada. O campo da pesquisa foi o município de Alcântara/MA, conhecido pela produção e distribuição do doce de espécie na região - os sujeitos deste estudo foram os moradores do município e um vendedor de doces da Cidade de São Luís /MA. Os resultados apontam que o "Doce de Espécie" é de cultura portuguesa, que veio por meio dos Açorianos e foi adaptada pelos escravos vindos da África para o Brasil. A valorização e preservação do "doce" dependem do incentivo aos produtores locais, de uma política pública e privada de valorização dos saberes e fazeres tradicionais do doce de espécie e do interesse dos jovens pela manutenção da tradição cultural quanto ao "saber-fazer" aplicado ao doce.
\end{abstract}

Palavras-chave: Saberes Tradicionais. Doce de Espécie. Alcântara/MA.

\begin{abstract}
The research presents the studies and analyzes of traditional knowledge and practices applied in the production of "Sweet species" in the municipality of Alcântara / MA. This work was the result of realisados studies in Study Group "Cultural Identities of Maranhão Gastronomy" - UFMA, and aimed to understand the knowledge and practices gastronomic involving the production of Sweet Species. Analyzing traditional knowledge through the influence of the Azores in the sweet preparation. Knowing the species of Sweet's relationship with the Divine Festival held annually in the city of Alcântara / MA. The methodology used in order to achieve the proposed objectives was through exploratory and descriptive research with qualitative approach and data collection through unstructured interview. The field of research was the municipality of Alcântara / MA, known for producing and kind of sweet distribution in the region - the subjects of this study were residents of the municipality and a candy seller of the city of São Luís / MA. The results show that the "Sweet Species" is of Portuguese culture, which came through the Azores and was adapted by slaves from Africa to Brazil. The appreciation and preservation of the "sweet" depend on the incentive to local producers, a public and private policy of recovery of traditional knowledge and the kind of sweet doings and young people's interest for maintaining the cultural tradition and the "know-how" applied the sweet.
\end{abstract}

Keywords: Traditional Knowledge. Sweet Species. Alcantara / MA. 


\section{Introdução}

Gastronomia e cultura, duas áreas que se entrelaçam, e que uma não existiria sem a outra, e ao mesmo tempo uma conserva a outra, pois a gastronomia revela a cultura de um povo, já a cultura são os costumes de um povo, onde podemos observar sua história, o seu modo de vida, suas crenças religiosas e outros. Para Beluzzo (2004) existe uma tendência de resgate da culinária tradicional em várias partes do mundo, gerando um movimento de preservação das raízes culturais, possibilitando a produção de patrimônios culturais locais.

Em meio a tantas descobertas e avanço tecnológico, se percebe uma tendência em cultivar e valorizar o que vem dos antepassados. Nesse contexto, destacamos que os saberes e fazeres gastronômicos construídos ao longo de muitos séculos de interação do homem com seu meio ambiente expressam valores relativos à história e a cultura dos povos. O presente trabalho teve como objetivo compreender os saberes e fazeres gastronômicos aplicados à produção do Doce de Espécie. O "Doce de Espécie" é um doce a base de coco típico de Alcântara, no estado brasileiro do Maranhão e considerado uma herança dos açorianos, sua popularização deve-se a sua distribuição durante a Festa do Divino, a festa é conhecida como um culto ao Espírito Santo, em suas diversas manifestações, é uma das mais antigas e difundidas práticas do catolicismo popular. Por se tratar de um alimento artesanal e tradicional, e consequentemente um elemento inserido na atividade turística, da cidade de Alcântara-MA, é que o interesse em desenvolver este trabalho se intensificou durante estudos realizados no Grupo de Estudo "Identidades Culturais da Gastronomia Maranhense" da Universidade Federal do Maranhão.

O valor cultural do ato e do modo de se alimentar é cada vez mais considerado como Patrimônio Cultural, pois a comida representa os povos, nações, civilizações, grupos étnicos, comunidades e famílias. As discussões sobre o entendimento e as estratégias de proteção do patrimônio cultural imaterial têm movimentado historiadores, antropólogos, sociólogos, gastrólogos e estudiosos de outras áreas, tanto brasileiros como estrangeiros (MÜLLER \& AMARAU, Revista Thema, 2012).

A cultura também acompanha essa transformação que ocorre com a mudança de gerações, além do avanço tecnológico, pois cada geração tem suas atrações e meios de se expressar, com isso, tanto a cultura, como a gastronomia, evoluem para se adaptar a novos costumes. Para Cunha e Almeida (1999) "é nas chamadas populações tradicionais que existe a possibilidade de continuidade do conhecimento tradicional, resultando na sua preservação e desenvolvimento". A gastronomia desenvolvida por essas populações está intimamente ligada a uma matéria-prima que possui características próprias de cada lugar, chamado de Terroir $^{1}$, nos pratos tradicionais utilizados alimentos regionais. As cozinhas regionais representam a fusão cultural de formação, colonização ou da própria evolução, que utiliza em sua composição basicamente ingredientes locais, produzidos na região.

\section{Referencial teórico}

$\mathrm{Na}$ alimentação humana se materializa a estrutura da sociedade, se atualiza a interação social, sócio ambiental e as representações sócio-culturais dos que têm em comum uma mesma cultura. A abstração conceitual da cultura se concretiza no prato (IKEDA, 2004, p. 289-292 \& MILLÁN, 2002, p. 277278). A gastronomia surge quando as pessoas passam a se alimentar por prazer, como afirma Fagliari (2005), quanto à mudança do significado

\footnotetext{
1 Termo de origem francesa (lê-se terroar), provém do latim popular (terratorium) alterado no galo-romano (territorium; territoire). Significa originalmente uma extensão limitada de terra considerada do ponto de vista de suas aptidões agrícolas, particularmente à produção vitícola. Usa-se também a expressão produtos de terroir para designar um produto próprio de uma área limitada, na ampliação do conceito desenvolvido por geógrafos franceses, é um conjunto de terras sob a ação de uma coletividade social congregada por relações familiares e culturais e por tradições de defesa comum e de solidariedade da exploração de seus produtos.
} 
simbólico da alimentação. "Foi à mudança no significado da alimentação, de simples necessidade de comer para prazer, que levou ao aparecimento de termos como 'gastronomia' e 'culinária'” (FAGLIARI, 2005, p. 2). Diante da temática abordada, Lody (2004, p. 150) e Canesqui (2005, p. 36), enfatizam que comer é antes de tudo um ato simbólico, tradutor de sinais, de reconhecimentos formais, de cores, de texturas, de temperaturas, entre outros. Consiste num ato que une memória, desejo, fome, significado, sociabilidade e ritualidade.

Gastronomia também está ligada às técnicas de cocção e ao preparo dos alimentos, ao serviço, às maneiras à mesa e ao ritual da refeição. Sendo assim tão abrangente, se pode entender que a cozinha e a culinária estão inseridas na gastronomia (FREIXA, 2008). A comida, ao longo da existência da humanidade, acumulou diversos símbolos e sentidos, que de acordo com Montanari (2010), definiu valores, construiu ideologias, elaborou modelos de comportamento, tudo isso determinado em torno do comer. Segundo Santos (2005, p 12), a gastronomia e a cultura, por serem um complexo sistema simbólico, composto de significados sociais, éticos, sexuais, religiosos, estéticos e identitários, passaram a ser objeto de estudo de sociólogos, antropólogos, historiadores e, inclusive, filósofos, a partir de meados do século XIX. Os estudos teóricos sobre a gastronomia continuam em constante reflexão, por meio da própria, pois esta explica e é explicada pelas manifestações culturais e sociais como espelho de uma época.

A gastronomia possibilita um vínculo identitário, podendo estar próxima de elementos, como festas e comemorações. Outro elemento que demonstra a proximidade entre os conceitos de gastronomia e de patrimônio cultural é a origem de ambos: apesar de já utilizado na antiguidade, o termo 'gastronomia' é retomado no século XVIII, por BrillatSavarin (apud FREIXA, 2008), que o entende como o conhecimento do homem à medida que ele se alimenta. Assim como os bens culturais materiais, também a gastronomia será pensada como estratégia de consolidação de uma identidade nacional.
Conhecimento tradicional é o conhecimento oriundo do saber-fazer das populações tradicionais e que não possui um processo universalizado de levantamento e registro (SIENA \& MENEZES, 2007). Existem iniciativas regionalizadas para o artesanato, música, referências linguísticas, uso de plantas medicinais, manejos ambientais, bem como para a gastronomia. "O conhecimento tradicional refere-se a um conhecimento empírico, desenvolvido ao longo de anos de práticas locais, envolvendo o meio ambiente e a cultura local vigente dentro de um processo de espaço e tempo determinados".

Ferreira; Jankowsky (2009) consideram que cada uma das etapas do sistema alimentar é carregada de significados culturais, formando a base de um conhecimento tradicional que guia a escolha do tipo de solo, da época de plantio, a observação da maré e da lua para a pesca, a seleção de sementes, a colheita, o trato e beneficiamento dos alimentos, a escolha da madeira para o fogo à lenha, o preparo dos alimentos, os hábitos à mesa, os tabus e o papel dos gêneros. Partindo-se dessa premissa torna-se numerosa a lista de conhecimentos dos povos, construídos ao longo de diversas gerações, atrelando a história e a identidade aos alimentos.

O contexto atual da globalização tende cada vez mais a homogeneizar o conhecimento, padronizando os processos e a produção. Para Cunha e Almeida (1999), é nas chamadas Populações Tradicionais que existe a possibilidade de continuidade do Conhecimento Tradicional, resultando na sua preservação e desenvolvimento. Entende-se que uma gastronomia tradicional pode ser preservada, disseminada e desenvolvida, quando houver a identificação e registro dos saberes e fazeres, uma tentativa de colaborar com a valorização e preservação garantindo perpetuação da memória e da identidade na comunidade. Somos o que comemos. Entendendo a estrutura culinária como o conjunto de regras e normas relacionadas à alimentação, incluindo os alimentos escolhidos, a organização do cardápio, as técnicas de preparo e os temperos, é possível identificar a culinária de uma região ou nação como uma particularidade cultural. 
Conforme o exposto, a Gastronomia Típica e tudo a ela relacionado, são percebidos como um marcador étnico, aquele que identifica uma localidade e é resultante da aliança cultural de formação, colonização ou da própria evolução. São cozinhas que perpetuam a influência da cultura gastronômica na vida social e nos costumes.

Vivendo como se vive, sob o signo da velocidade e a égide da angústia (de tempo, de espaço residencial, de alimentos, de tranquilidade, de alegria) estão os homens da desintegração atômica perdendo a legitimidade do paladar. Para Cascudo (1983), a alimentação fora do lar é um fator negativo, pois levou à decadência nacional da refeição doméstica, o abandono dos pratos tradicionais no cardápio de certos grupos sociais [...], onde cada vez há menos refeição e cada vez mais comidas facilmente encontráveis [...]. Até o item anterior, observaram-se ações que contribuíram para uma perda gradativa dos saberes e fazeres da gastronomia tradicional. Em resposta a essa questão surge em 1986 um movimento social e econômico cujo objetivo seria resguardar toda tradição e costumes por meio da alimentação, o slow-food ${ }^{2}$.

Como fora amplamente exposto, as práticas e representações alimentares de uma nação não decorrem somente do mero instinto de sobrevivência ou do prazer do homem em alimentar-se, mas, principalmente de sua história, geografia, clima e organização social, podendo ser incluída no rol de bens que compõem os Patrimônios Culturais Imateriais.

\footnotetext{
2 Uma organização não governamental fundada por Carlo Petrini em 1986 com o objetivo de promover uma maior apreciação da comida, melhorar a qualidade das refeições e uma produção que valorize o produto, o produtor e o meio ambiente. "Slow food" é uma expressão da língua inglesa que significa, literalmente, "comida lenta". É uma referência à busca da organização por uma maior lentidão no processo de produção e degustação dos alimentos, visando a um aumento do prazer proporcionado pelos mesmos, num contraste com o fast-food. Defende a necessidade de informação do consumidor, protege identidades culturais ligadas a tradições alimentares e gastronômicas, protege produtos alimentares e comidas, processos e técnicas de cultivo e processamento herdados por tradição, e defende espécies vegetais e animais, domésticas e selvagens. O alimento, portanto, deve ser bom, limpo e justo, o que significa que ele deve ser saboroso, deve ser produzido de forma a respeitar o meio ambiente e os preços devem ser justos, tanto para quem os produz, quanto para quem os consome.
}

Há também um resgate e preservação de nossas culturas por meio do Instituto do Patrimônio Histórico e Artístico Nacional - IPHAN. De acordo com a PORTARIA № 92, DE 5 DE JULHO DE 2012, no Art. 2응 o IPHAN tem como missão promover e coordenar o processo de preservação do patrimônio cultural brasileiro visando fortalecer identidades, garantir o direito à memória e contribuir para 0 desenvolvimento socioeconômico do País. O § $1^{\circ} \mathrm{diz}$ que: "É finalidade do IPHAN preservar, proteger, fiscalizar, promover, estudar e pesquisar o patrimônio cultural brasileiro, na acepção do art. 216 da Constituição Federal", Instituto do Patrimônio Histórico e Artístico Nacional [IPHAN] (2012).

Conforme a Organização das Nações Unidas para a Educação a Ciência e a Cultura [UNESCO] 2005 (apud IPHAN), Patrimônio Cultural Imaterial são as práticas, representações, expressões, conhecimentos e técnicas (junto com os instrumentos, objetos, artefatos e lugares que lhes são associados), que as comunidades, os grupos e, em alguns casos, os indivíduos reconhecem como parte integrante de seu patrimônio cultural. Este que se transmite de geração em geração, é constantemente recriado pelas comunidades em função de seu ambiente, de sua interação com a natureza e de sua história, gerando um sentimento de identidade, contribuindo para a promoção do respeito à diversidade cultural e à criatividade humana (IPHAN, 2006).

Não se preserva um prato, mas sim o saberfazer. (MÜLLER \& AMARAU, Revista Thema, 2012). Patrimônio Cultural Imaterial é um bem de natureza intangível, de caráter dinâmico e intimamente associado às práticas e representações culturais. Dentre as manifestações patrimoniais no mundo contemporâneo, a Constituição Federal do Brasil (1988) define como Patrimônio Imaterial "os modos de criar, fazer e viver, expressos em rituais, celebrações entre outros". O mesmo documento garante a preservação do Patrimônio Imaterial brasileiro.

A inserção dos saberes e fazeres da gastronomia como patrimônio cultural imaterial, analisando as ações dos órgãos públicos nacionais e 
internacionais, no que diz respeito à preservação do conhecimento tradicional oriundo das práticas gastronômicas é uma prerrogativa para preservação e proteção do conhecimento tradicional gastronômico reconhecido. Esse conhecimento cultural é, sobretudo, tácito e compreende os saberes e fazeres transmitidos de pais para filhos que se encontram ameaçados frente ao fenômeno da globalização.

\section{Metodologia}

No intuito de alcançar os objetivos propostos, optou-se pela pesquisa exploratória e descritiva, quanto à fundamentação teórica, é documental e bibliográfica. Desta forma empregou-se para coleta de dados instrumentos como a entrevista não estruturada com vistas a explorar os aspectos teóricometodológicos sobre a produção do "Doce" em Alcântara - MA, optou-se ainda abordagem qualitativa. As entrevistas foram feitas em um primeiro momento durante a festa do Divino Espírito Santo, em maio, e no segundo momento após a festa, no mês de junho. O campo da pesquisa foi o município de Alcântara - MA, que teve como objeto o Doce de Espécie e os sujeitos deste estudo foram os moradores do município de Alcântara - MA, os critérios para escolha da amostra foram: pessoas que produzem artesanalmente o Doce de Espécie, que fazem do Doce uma fonte de renda (produtores e vendedores), as que contribuem na Festa do Divino, e as reconhecidas por ainda manter a tradição na preparação do Doce, perfazendo uma amostra de 10 entrevistados.

\section{Resultados e discussões}

A importância dessa pesquisa evidencia a influência do doce de espécie na cultura local e na atividade turística do Município de Alcântara-MA. Os resultados apontaram que até hoje, a tradição do saber-fazer o doce de espécie, sobrevive por conta da Festa do Divino, do turismo e das gerações de alcantarenses que perpetuam a cultura de seus antepassados.
Objetivando expor de forma clara e organizada os resultados analisados, serão apresentados os relatos das entrevistas realizadas com os sujeitos do estudo, possibilitando uma compreensão do universo pesquisado.

Alcântara cidade-monumento, histórica fica à uma hora de São Luís, foi tombada pelo Instituto do Patrimônio Histórico e Artístico Nacional - IPHAN, em 1948, devido aos casarões e fachadas revestidas de azulejos coloridos, portais emoldurados de pedras de lioz, além da importante manifestação cultural e religiosa denominada 'Festa do Divino'. Alcântara está localizada no continente, a $30 \mathrm{~km}$ da capital (LOBATO, 1992).

Os produtos tradicionais também são denominados 'produtos com história', pois se constituem e fazem parte da história social de uma determinada cultura. Vindos de um longo tempo, através de gerações que os foram produzindo e recriando, esses produtos marcam um processo que reúne relações sociais e familiares, num encontro entre o saber e a experiência; portanto, a produção desses alimentos é, ainda, uma arte construída ao longo do tempo através da tradição familiar (ZUIN, 2008, p. 13).

De acordo com a fala do autor, é possível compreender por meio dos relatos dos entrevistados, o entendimento sobre a importância histórico cultural envolvendo o "Doce de Espécie".

Eu conheço o doce de espécie da festa, mais já dizia minha avó que ele foi trazido pelos Portugueses, e também outros antigos diziam que este doce tem em Portugal também, mais o daqui é diferente, porque pode ter sido trabalho dos escravos, e pela mistura de raças, ficou diferenciado do de Portugal. Eu acho que esse doce veio de lá, mais como eu falei, que para agradar os senhores os escravos daqui de Alcântara fizeram o doce mais caprichado (ENTREVISTADO A).

Eu não sei realmente a origem desse doce, mais os antigos já diziam que ele é de origem portuguesa, que veio com os açorianos na época do descobrimento e das grandes navegações (ENTREVISTADO B).

A fala dos entrevistados $A$ e $B$ fazem alusão ao que diz Silva (2012), "sendo uma das iguarias mais apreciada pelo Imperador, o doce de espécie é de origem portuguesa, da llha de São Jorge, no 
arquipélago de Açores". Ainda segundo o autor o Doce de Espécie, chama-se "espécie", devido ao uso de várias especiarias.

Destas linhas sobressai, obviamente, a importância desempenhada pelos Açores na colonização do território brasileiro. [...] Há que se reconhecer, no entanto, que a emigração açoriana, induzida ou não por propósitos da Coroa, tem a particularidade de ser essencialmente colonizadora, de caráter definitivo, baseada em movimentações familiares (CORDEIRO \& MADEIRA, 2003).

Aqui em Alcântara sempre houve muitas histórias, mas eu aprendi lá dentro da festa, quando eu participava, que este doce era feito pelos escravos que esperavam por Dom Pedro II, isso é a única coisa dessas histórias que eu ouvi e sei te falar (ENTREVISTADO C).

Esse doce na verdade eu não sei do significado dele e de onde ele veio, o povo daqui fala que veio dos portugueses, e que 0 doce foi adaptado pelos escravos, e se tornou esse nosso Doce de Espécie (ENTREVISTADO E).

Conforme Muller (2003) houve a fusão do conhecimento de técnicas culinárias dos açorianos, com a matéria-prima brasileira, que era conhecida pelo ameríndio.

Eu ouço falar que é portuguesa, e que o povo de Alcântara imitou os doces de Portugal para agradar ao Imperador que iria visitar a cidade, visita esta que não aconteceu (ENTREVISTADO F).

Dizem que essa receita do doce veio de Açores em Portugal. Os portugueses vieram para o Brasil chegaram até o Maranhão, inclusive eles fazem a festa do Divino Espírito Santo em homenagem à coroa portuguesa, então de acordo com as histórias daqui de Alcântara ele é original de lá (ENTREVISTADO H).

As falas dos Entrevistados A, B e C, E, F, H fazem referência ao que Freixa e Chaves (2008) relatam que "a gastronomia brasileira começa a se consolidar a partir do século XVII, com a implementação dos engenhos para a produção de cana-de-açúcar no Nordeste, pois é na casa grande que se destaca a influência da cozinha portuguesa, com as técnicas culinárias e a feitura dos doces".
As receitas eram das Sinhás, mas as adaptações foram feitas com os ingredientes que havia por aqui, moldados pela mão da escrava africana. Zelinda Lima, culinarista maranhense, também fala em seu livro (Pecado da gula), que é herança portuguesa a arte de preparar doces entre os maranhenses, assinalando então, progresso de aculturação (LIMA, 1998).

Essa coisa de uma pessoa dizer que a história veio de Portugal, pra mim, nada disto eu coloco fé, porque eu não sei, eu não estava lá, não era nem gente na época, porque hoje em dia uma pessoa escreve um livro e o colocar o que quer e quem ler depois vai achar que estar certo, por isso que pra mim ela não tem origem nem de Portugal, eles dizem mais eu não posso afirmar, nem de Açores, nem porque veio uma coroa, não sei se é verdade, mais aqui contam essa história. Por isso pra mim existe a festa e o doce de espécie de Alcântara (ENTREVISTADO D).

Observa-se que a maioria das falas é de doceiros, moradores antigos e participantes da festa do divino, que convivem com essa cultura há décadas, eles relatam que o doce tem traços lusoaçorianos, pois desde que nasceram, afirmam que conhecem essa história, e que esta é passada de geração a geração. Farias (1998) aponta que essa cozinha é de "base açoriana.

A gastronomia açoriana é caracterizada por peixe, marisco, carnes de vaca, queijo, frutas (bananas, maçãs, maracujá, araçá), e a doçaria com sinais de tradição conventual assumem especial força no conjunto de bolinhos e docinhos típicos de cada ilha, que surpreendem pelos nomes e sabor (http://www.visitazores.com)

A principal característica do povo açoriano desde o povoamento das ilhas até os dias de hoje é a imigração. [...] Hoje, os motivos da imigração geralmente se baseiam em três grandes blocos: o econômico, devido às mudanças no sistema capitalista; o geográfico, mudanças climáticas, abalos sísmicos, vulcões, tsunamis e outros fenômenos naturais; e o bélico, onde a destruição local ou o medo do alistamento militar fazem ocorrer os fluxos migratórios. [...]. Os Açorianos passaram pelos três fenômenos e um dos principais destinos foi o Brasil, e 
contribuíram e muito para o povoamento do nosso país tanto numericamente, como na defesa das fronteiras e principalmente culturalmente, trazendo suas tradições católicas, sua culinária, o trabalho na terra e no mar.

A todo o momento em que o açoriano se viu ameaçado por uma quebra de colheitas, estiagem, dificuldades comerciais, diminuição dos fluxos de mercadorias e estrangeiros, vulcões, sismos ou pressões políticas e religiosas; o açoriano olha para o mar e se lança à imigração. [...] Nos séculos XVII e início do XVIII a grande preocupação era garantir o domínio territorial do Norte do país que sofria ameaças francesas, inglesas e holandesas. Ocupar a costa brasileira era fundamental, já que no início do século XVII fora a França quem chegou a estabelecer na região do Maranhão uma pequena colônia, desrespeitando o tratado de Tordesilhas. Na época Portugal estava anexado a Espanha devido a União Ibérica, e o governo Espanhol, com medo de os franceses invadirem suas terras mandou uma força militar portuguesa de 400 homens em 1615, que expulsou os franceses.

A imigração açoriana para o Brasil teve início no Século XVII, em 1619, com trezentos casais que chegaram ao Maranhão. [...] Naquela época o norte do país era selvagem, não era marcado pela busca do ouro, ou as grandes plantações de algodão; o açoriano, como sempre, ficou com a tarefa mais difícil, de desbravar, garantir fronteiras. No início da colonização brasileira o açoriano dividia o papel de povoador com os jesuítas que catequizavam os índios. Estes 300 casais chegavam a mil pessoas, pois vinham com seus filhos e criadagem, então para os padrões da época, era uma considerável massa de pessoas, tanto que, logo tiveram influência para ocupar importantes cargos na administração regional (GONÇALVES, 2010). Podemos ser considerados o reflexo desse povo, pois toda a cultura e culinária que temos hoje, por mais que tenha sofrido adaptação, traz consigo os traços dos açorianos, que muitas vezes vinham pela escassez de alimento ou por causa de tragédias naturais. Vale destacar que eles influenciaram a história do povo alcantarense, e até hoje é possível perceber a presença marcante dessa contribuição, na Festa do Divino e na culinária.

Tanto no sul do país como nesta região norte, as festas regionais ou católicas trazidas pelo açoriano se moldaram com a cultura local deixando raízes profundas, como a festa do boi de mamão, retirada de um bom touro de uma fazenda, para fazer a farra do boi, festa que tinha duração por vários dias, até o touro cair cambaleante de exaustão, esta festa vem da tourada de corda da ilha Terceira e das 'Festa do Divino', em Alcântara, no maranhão. Além da própria festa do divino espírito santo que também é comemorada no norte do país, embora muito mesclada com a cultura africana local (GONÇALVES, 2010).

\begin{abstract}
O doce ele veio de tradição, eu era menina e minha avó ia ajudar na casa do festeiro, aí eu ia com ela, daí por diante eu o conheci e comecei a participar da festa do divino, e como participante agente sempre ajuda na cozinha, e foi através disso que eu comecei a aprender a fazer o doce (ENTREVISTADO A).

Aprecio muito a festa e amo fazer este doce, ele foi passado da minha avó para minha mãe, e da minha mãe para mim, e não sei se futuramente algum filho meu vai levar adiante essa cultura que já estar na minha família a século (ENTREVISTADO $\mathrm{H}$ ).
\end{abstract}

Já de acordo com o entrevistado B e C a aprendizagem do doce pode acontecer em duas situações, as que ocorrem através do conhecimento passado por gerações e as que conheceram por participar da festa do divino espírito santo.

Eu tinha 16 anos de idade quando comecei a ajudar nas casas de festeiro durante a festa do divino, e comecei a trabalhar com o doce de espécie em 1983, foi através da festa que eu o conheci e aprendi a fazê-lo. Essa cultura na minha vida não veio de tradição, pois meus pais nunca participaram da festa, inclusive minha mãe é evangélica (ENTREVISTADO B).

Quando eu nasci já existia essa festa, meus pais foram festeiros como muitos outros, mais não foi o fato de meus pais ter participado que me levou a participar não, eu comecei a participar da festa porque todos de Alcântara participavam. O doce de espécie desde quando começou esta festa aqui, que eu nem era nascido, já era tradicional dela, eu durante todo esse tempo nunca vi festa sem o doce de espécie (ENTREVISTADO C). 
Hoje a gente se preocupa com a falta de desinteresse dos jovens pela nossa cultura, que também é a deles, hoje nenhuma menina quer ser caxeira, ou segurar a bandeirinha, ou então ajudar na cozinha com os doces, aí em vez de estarem participando da festa que mostra nossa tradição elas preferem estar na frente de um computador. As últimas caxeiras são três, e já são de idade (ENTREVISTADO A).

O doce de espécie é muito cheio de detalhe e trabalho, e não é todo mundo que consegue trabalhar com ele, por isso que antigamente ele só era visto duas vezes por ano, e daqui a alguns anos a gente vai ter dificuldade em fazer o doce na festa, porque as pessoas mais velhas que eu conheço que faziam o doce, já foram embora, só tem três doceiras, onde uma delas é a entrevistada E, onde já são de idade, e algumas dessas já não fazem mais o doce, e alguns jovens daqui não tem a responsabilidade, nem o meus filhos que eu faço o doce todo dia não ligam muito, eles me ajudam raramente, porque logo o doce é muito trabalhoso (ENTREVISTADO B).

Eu não sei se futuramente algum filho meu vai levar adiante essa cultura que já estar na minha família a século. Um dia estávamos conversando aqui em casa, sobre o porquê que o jovem de hoje não conhece sua própria história, porque muitos deles não tem interesse de saber de onde veio e de onde tudo partiu, hoje eles só querem saber de computador, celular, vídeo game, eles estão deixando a história morrer. Aqui em casa mesmo eu tenho um irmã de 17 anos e esta não sabe nem ralar um coco [...]. Então a gente vem lutando com a festa, porque a festa de hoje não é festa do divino que Alcântara registrava antes, essa festa mudou muito, essa mudança agente vem buscando ela bem lentamente para que as coisas não tornem a festa outra festa, porque quando a festa perder o brilho que ela tem, automaticamente ela se acaba, porque as pessoas vêm ver a festa pra ver o que ainda é conservado, quando se deixar de conserva, ou quando outro lugar copiar, ela se tornara comum, as pessoas irão deixar de vim para a festa. Olha no Maranhão tem 66 festas do divino, mais todos vêm prestigiar a festa daqui de Alcântara porque ela é diferenciada e só a nossa tem 0 doce de espécie (ENTREVISTADO H).

Zuin (2008) ratifica este fato, afirmando que na atualidade, a história familiar - sua memória, sua organização e seu patrimônio cultural - têm sido esquecidos, não só no que se refere à alimentação, mas a outros valores. As novas famílias têm deixado de transmitir para os seus filhos os costumes das relações entre os familiares, os rituais das datas comemorativas, a rotina do dia a dia, as receitas da família, isto é, os valores construídos por gerações.

\begin{abstract}
O descaso do município é muito grande, que foram distribuídos livros e dossiê para se fazer o tombamento da Festa do Divino, foi tudo uma coisa pré-acertada, para que primeiro os mordomos festeiros lessem o livro e no domingo do Espírito Santo, quando tivessem as autoridades, seriam coletadas assinaturas para iniciar o processo, mais nada disso foi feito. O IPHAN tem interesse de salvaguardar tudo que é nosso, tanto patrimônio material como imaterial, mais falta interesse dos órgãos que são responsáveis pela Festa. Mas alguém tem que ter interesse, nós não podemos sair pedindo para esses responsáveis fazer o que era pra eles fazerem (ENTREVISTADO J).
\end{abstract}

Quando eu cria na imagem de escultura, eu preservava, mas agora eu sou evangélica e não creio mais nessas coisas, e não me interesso mais em estudar está cultura, meu estudo hoje é a bíblia e eu também sou compositora, toco violão, portanto pra mim tanto faz se ela está se perdendo ou não (ENTREVISTADO C).

\section{A Festa do Divino de Alcântara - cidade} histórica marcada por um patrimônio de casas e sobrados do século XIX é umas das mais expressivas do calendário cultural e religioso do Maranhão. Com duração entre 12 e 15 dias, sua corte completa, este ano, formada por 10 festeiros, tem seus nomes revelados, no Domingo de Pentecostes, quando logo após a procissão, se dá a leitura do pelouro ${ }^{3}$ - a primeira cerimônia da nova festa - a partir da qual toda a cidade passa a vivê-la intensamente. Cada um dos festeiros alcantarense do ano prepara-se para fazer a festa numa casa, que geralmente é cedida ou alugada para esse fim, sendo que o Imperador ou a Imperatriz conta com a Casa do Divino, um sobrado de dois pavimentos, mantido pelo Governo do Estado, para funcionar como a sede do Império. Em cada casa em que se dá a festa é feita uma ambientação com a Tribuna, mesas de doce (com destaque para o

\footnotetext{
3 Desde o ano de 1930 o pelouro registra nomes de imperadores e imperatrizes que se sucederam na festa tradicional da cidade. O senhor Galdino deixou o pelouro como herança para o Sr. Ricardo leitão que foi sucedido pelo Sr. Moacir Amorim. Instituída pela rainha Dona Isabel, em Portugal, no século XII, a festa do Divino foi trazida para o Brasil no século XVI e desde então acontece em diversas cidades brasileira, entre elas Alcântara onde a tradição é secular.
} 
famoso "doce de espécie"), bem como figuras da Corte, cortejos e músicos.

O doce não pode faltar na festa do divino, ele é muito importante na mesa da festa, desde que eu me entendo por gente eu nunca vi uma festa sem doce, todas as casas da festa fazem muitos doces, para que todos os visitantes possam comer, e em todos os pratos que vão à mesa do banquete das casas de festa ele tem que estar incluído (ENTREVISTADO A).

A relação entre o doce de espécie e a festa de divino é que ele sempre acompanhou a mesa, e nunca foi visto em Alcântara uma festa sem doce de espécie (ENTREVISTADO B).

O doce é exposto na festa do divino desde que ela existe, mais sobre essa relação não sei mais nada disso, pois hoje não pratico mais a festa, hoje minha fé mudou, e eu só vivo para meu Senhor e Salvador que é Jesus, e o meu doce não tem mais relação com a festa, por isso não sei the falar sobre isso (ENTREVISTADO C).

Este doce é uma das regalias da festa, uma especialidade muito importante tanto pra festa como para nossa cidade, apesar de na festa existir vários tipos de doce, mais este é o mais apreciado durante a festa e o mais procurado durante todo 0 ano na cidade (ENTREVISTADO G).

Segundo Silva (et al., 2012), o Imperador Dom Pedro II foi convidado ao mesmo tempo por duas famílias de Alcântara, divididas pela política, para que visitasse a cidade e se hospedasse em suas casas. Com o intuito de obter prestígio e aumentar sua influência na política local, cada uma das famílias começaram a construir um castelo e, segundo eles, a família cujo Imperador escolhesse para se hospedar receberia o título de "Barão de Alcântara". O conflito acirrou-se e, sabendo desse fato, ele nunca visitou a cidade. A população esperou por alguns dias e, resolveram fazer a festa assim mesmo, simulando a presença da corte, substituindo todo o séquito e cortejo imperiais, por crianças com trajes reais. $O$ povo saiu às ruas em cortejo, dirigindo-se à igreja, onde Ihes aguardavam farto banquete com muitas iguarias, sendo uma delas a mais apreciada pelo imperador: "o doce de espécie".

O doce na festa é porque antigamente as pessoas nobres, quando recebiam visitas em casa serviam doces, chocolates, e isso é um habito Português que os nobres de Alcântara incorporaram na cultura e na festa (ENTREVISTADO G).

O doce na festa é para recepcionar os visitantes nas casas de festas, ele também faz parte, além de ser um dos principais iguarias servidas durante a festa (ENTREVISTADO D).

Aprecio muito a festa e amo fazer este doce, e acredito que ele na festa significa receptividade. A maneira que as pessoas daqui recepcionam as pessoas que vêm prestigiar a festa é oferecendo esse doce. Esse doce na festa representa a recepção do povo de Alcântara, por isso não pode faltar nas casas de festa (ENTREVISTADO H).

Portanto, é, sobretudo, a partilha que importa, mais do que a própria composição da refeição, na medida em que se tratam, no presente caso, os alimentos e bebidas mais elementares. O que funda a refeição ou o banquete é esta comensalidade entre os participantes, que remete a uma das expressões da solidariedade básica do grupo familiar ou da comunidade (FLANDRIN, 1998).

A comensalidade, tanto do ponto de vista religioso como profano, foi sempre vista como maneira importante de promover a solidariedade e de reforçar laços entre membros de um grupo. Entre os que comem e bebem juntos há, em geral, vínculos de amizade e obrigações mútuas, pois a fraternidade e a afinidade são inerentes à comensalidade (FRANCO, 2001).

Para Cunha e Almeida (1999) é nas chamadas população tradicional que existe a possibilidade de continuidade do Conhecimento Tradicional, resultando na sua preservação e desenvolvimento. A gastronomia desenvolvida por essas populações está intimamente ligada a uma matéria-prima que possui características próprias de cada lugar, chamado de Terroir, sendo, nos pratos tradicionais, utilizados alimentos regionais. As cozinhas regionais representam a fusão cultural de formação, colonização ou da própria evolução, que utiliza em sua composição basicamente ingredientes locais, produzidos na região.

Eu tenho 55 anos de festa do divino, e eu te falo que quem conhece o preparo desse doce bem é o "entrevistado B", apesar de ele ser uma pessoa nova, ele sabe muito deste doce, 
porque ele pegou a essência do preparo durante as festas, pode ter outros, mais pra mim igual a ele não tem, e ele já tem essa pratica como profissão, pois o mesmo tirar sua renda do doce, ele realmente tem contato com o doce dia a dia, ele não se guarda apenas para o preparo do doce na festa, por isso o doce dele é bem aceito por todos, porque ele tem a pratica (ENTREVISTADO D).

Primeiro descasca o coco, depois quebra e tira a pele, depois rala, depois mistura com os ingredientes (manteiga, açúcar, cravinho e ovo) aí coloca para cozinhar até dar o ponto, depois que dá o ponto deixa esfriar, aí pega o trigo e molha, no trigo vai a manteiga e água com um pouquinho de sal, aí amassa o trigo e depois esticar com o rolo, logo em seguida vai abrindo a massa, a seguir é só corta a massa do formato que preferir, tem 0 de tartaruguinha, coração, folha e etc, depois coloca essas massas já cortadas na forma untada, em seguida coloca o recheio nelas, aí é só fazer o arranjo do doce que também é de trigo, e é só usar a imaginação e fazer a decoração que quiser em cima do doce, pode formar uma flor ou qualquer outro desenho, também tem um detalhe que é o talinho que também é feito de trigo que agente coloca para quando a pessoa for comer o doce segurar nele, ele é meio durinho mais pode ser comido, mais os meus o coloco muita manteiga para ficar molinho, aí é só levar ao forno de barro (ENTREVISTADO A).

Primeiro você quebra o coco, tira a casca, tira a pele, rala, coloca na panela para cozinhar, junto com ele vai o açúcar, a manteiga, os ovos e o cravinho, e dependendo da quantidade de coco se acrescenta uma certa quantidade de água, para o açúcar dissolver e ficar com um pouco de calda, e então é só misturar tudo na panela e colocar para cozinhar sem parar de mexer, porque se não queima, depois faz a massa de trigo, que é quase como uma massa de pastel, só que a diferença entre essas duas massas é que na do doce vai a manteiga e a do pastel é óleo. Depois espicha a massa e corta na forma que preferir, aí coloca na fôrma untada com manteiga, logo em seguida coloca-se o recheio do coco, aí para finalizar faz uma tirinha com a massa do trigo para enfeitar, aí é só levar no forno. Uns ficam um pouco tostadinho aí você tem que limpar, aí é embalado na bandeja para a venda (ENTREVISTADO B).

Agente quebrar muitos cocos, tirar as casca grossa e depois a fina, depois leva pra ralar, depois refoga e coloca para cozinhar com os outros ingredientes, depois faz a massa de trigo para fazer a forma do doce, aí enche com o recheio de coco essa massa cortada com a forma que desejamos, e depois faz as tirinhas para enfeitar, e depois é só colocar para assar (ENTREVISTADO E).
Segundo Silva (2012) [...] o doce não tem medida e nem proporções exatas. A massa é medida no olhar e o ponto da massa é dado pelo toque (tato) e provas (paladar), embora, existam hoje receitas que tem todas as medidas.

As elaborações tradicionais não se limitam somente a receitas diferentes, mas envolvem ingredientes, métodos, preparações, formas de sociabilidade e sistemas de significados que se fundamentam nas características do território em que está inserida e na experiência vivida de quem a produziu. Ginani (2005) afirma que as receitas regionais são conhecidas e valorizadas por constituírem os hábitos alimentares nativos, sendo elaboradas com os ingredientes disponíveis na região e preparadas com técnicas transmitidas de geração a geração.

O doce de Portugal leva ovo em sua receita, assim como a queijadinha e o nosso próprio doce de espécie, que além do ovo leva também cravinho, manteiga, açúcar e o trigo que é para fazer o formato, que são de folhas, corações e tartarugas, e outros, depende da imaginação de cada doceiro (ENTREVISTADO H).

Sobre a receita eu não posso dizer, apesar de cada um fazer do seu jeito, mais minha maneira e os ingredientes que eu uso é segredo meu (ENTREVISTADO C).

Mais o doce não tem mistério, porque é o coco agente rala, depois de ralado acrescenta a manteiga, os ovos, o açúcar e o cravinho, depois leva-se ao fogo e esperar dar o ponto, aí é só colocar para esfriar. Depois do recheio pronto é só fazer a massa que é com o trigo, manteiga, água e sal, depois da massa pronta é só leva - lá para o cilindro para estica-la, depois de esticada é só corta a massa no desenho que você preferir, aí se coloca o recheio em cima da massa já cortada, que é em formato de tartaruga, folha ou coração, depois é só levar o doce ao forno para assar (ENTREVISTADO F).

É preparado com coco, açúcar, cravinho e manteiga, aí vai ao fogo e esperar dar o ponto, depois se faz uma massa de trigo, para fazer um suporte para colocar o recheio, faz também umas tirinhas que vão à cima do doce, que servem de enfeite, e também para suporte para segurar o coco, também tem um cabinho, que servi para segurar o doce e as forma do doce são: coração, folha, tartaruga e dália, e esse doce é assado em um forno de barro (ENTREVISTADO G). 
A qualidade dos produtos tradicionais é o que os diferencia dos produtos industrializados (tipo commodities), uma qualidade que parte da organização, da estrutura e do cuidado no feitio. Nesse sentido, o resgate dos produtos tradicionais busca valorizar as produções artesanais (arte + trabalho), salientando a construção cultural e identitária de determinada região (ZUIN, 2008).

A cultura também acompanha essa transformação que ocorre com a mudança de gerações, além do avanço tecnológico, pois cada geração tem suas atrações e meios de se expressar, com isso, tanto a cultura, como a gastronomia, evoluem, para se adaptar a novos costumes.

O conceito de alimento-memória, definido por Santos (2004), remete às iguarias que, ao serem consumidas, nos conduzem a uma experiência nostálgica e uma ligação com conteúdos simbólicos que podem estar associados tanto à memória individual (lembranças pessoais da infância) quanto à memória coletiva (lembranças de situações experimentadas - ou "herdadas" dos grupos sociais) o que permite exercitar a chamada memória gustativa (GIMENES, 2008).

Hoje o doce é vendido diariamente pelo entrevistado $B$, eu já vendi muito para São Luís há uns 13 anos atrás, mais por ele ser muito cansativo, e na época que eu fazia ele era ralado na mão, sendo que hoje já tem uma máquina que rala, mais não tenho mais condições de fazer por causa da idade, mais dar para vender e viver do doce, a procura é grande, pois as pessoas gostam muito deles. Quando eu parei de fazer eu peguei pra vender os doce que o entrevistado $\mathrm{B}$ fazia, e esse têm muita credibilidade entre os compradores (ENTREVISTADO A).

Esse doce só era visto aqui em Alcântara-MA durante a festas do divino, que eram distribuído nas casas de festa, e na festa de são Sebastião ele era vendido. Daí eu comecei a ver o doce como fonte de renda, então comecei a vendê-lo em um hotel que tinha aqui, cujo nome era pousada pelourinho, e as pessoas deste hotel, me ajudaram e começaram a vender esse doce pra mim em 2000, e até hoje eu faço doce pra vender. Antes de começar a vender o doce, eu era concursado de vigilante mais larguei, e já faz onze que eu larguei o emprego pra fazer o doce, onde percebi que ganharia muito mais com a venda do doce de espécie, e hoje eu vivo dele. Antigamente eu vendia o doce só aqui em Alcântara e hoje já tenho cinco Pessoas que eu forneço em São Luís, e eu mando toda semana (ENTREVISTADO B).

Eu deixei de costurar, e comecei a fazer o doce e licor, que são produtos da festa do divino, através deles eu encontrei uma fonte de renda (ENTREVISTADO C).

Eu gosto de fazer o doce, minha profissão é fazer doce, eu amo isso, não é só pelo dinheiro não, porque assim uma coisa que você faz com amor é bom, pois eu gosto do que eu faço, além de trabalhar com outras coisas, mais minha principal fonte de renda é do doce, faço muitas encomendas grandes 2000, 3000, essas encomendas já foram para Brasília e São Paulo, mais assim é muito trabalhoso, mais esse trabalho em mim se torna prazer, e quando a gente ama uma coisa, e por mais que seja trabalhosa, a gente não sente dificuldade (ENTREVISTADO H).

Sou vendedor da feirinha do reviver, e eu comercializo o doce de espécie a 3 anos. Meu principal fornecedor é o entrevistado $B$, de Alcântara, nos dois primeiros anos eu comercializei exclusivamente com ele, depois eu experimentei adquirir de outro fornecedor daqui de São Luís, porem o padrão de qualidade não era semelhante ao de Alcântara, este por ser feito do forno a lenha, eu acho que isso tudo influencia, tanto no sabor quanto na textura (ENTREVISTADO I).

O conteúdo das falas dos entrevistados está relacionado ao que diz Zuin (2008), a produção de alimentos tradicionais é mais que uma forma de gerar renda, é um processo que reúne relações sociais e familiares, num encontro entre o saber e a experiência, por isso é considerado uma arte construída ao longo do tempo.

O conhecimento cultural é, sobretudo, tácito e compreende os saberes e fazeres transmitidos de geração a geração, que é a identidade de um povo, e se encontram ameaçados frente ao fenômeno da globalização. Segundo Hall (2006, p 12), "as velhas identidades, que por tanto tempo estabilizaram o mundo social, estão em declínio, fazendo surgir novas identidades e fragmentando o indivíduo moderno, até aqui visto como um sujeito modificador". As elaborações tradicionais não se limitam somente a receitas diferentes, mas envolvem ingredientes, métodos, preparações, formas de sociabilidade e sistemas de significados que se fundamentam nas características do território em que está inserida e na experiência vivida de quem a produziu. Ginani (2005) 
afirma que as receitas regionais são conhecidas e valorizadas por constituírem os hábitos alimentares nativos, sendo elaboradas com os ingredientes disponíveis na região e preparadas com técnicas transmitidas de geração a geração.

Agente ver durante a festa que muitas pessoas vão para o hospital de cansaço, porque é muito trabalhoso fazer a festa e o doce de espécie, mais esse cansaço é satisfatório, pois a gente tem amor por essa tradição, depois que passa a festa estão morrendo de cansaço, mais ficamos com saudade, já tenho 17 anos dentro da festa, é uma alegria só, a gente trabalha junto é uma harmonia só. Hoje sinto saudade, pois não posso mais participar das confecções dos docinhos da festa, eu tenho amor por isso, e hoje só vejo passar de longe (ENTREVISTADO A).

Eu nunca vi festa sem doce, e hoje temos que ter os doces todos os dias em Alcântara, pois os turistas quando chegam a primeira coisa que perguntam é sobre o doce e querem logo prová-lo (ENTREVISTADO B).

Por isso que se diz, se algum turista vier a cidade e não procura uma das casa que vende o doce ou durante a festa ir nas casas de festeiro para provar, dessa coisa nascida de Alcântara, não sabe o que é a festa do divino e nem o doce, porque todo mundo que chega aqui não procura por outra coisa a não ser o doce de espécie, pois este doce conta um pouco de nossa história (ENTREVISTADO D)

A importância do doce é o seu próprio desenvolvimento, porque hoje quando o turista vem para nos visitar, ele já vem com o conhecimento sobre o que fazer aqui na cidade, e sempre querem sempre olhar os monumentos, as ruínas e experimentar o doce de espécie, que independente da festa do divino. Os turistas perguntam logo pelo Doce, daqui uns dias ele vai ser vendido não só no Maranhão, mais creio eu que ele ira conquistar outros estados, assim como conquista cada turista que vem aqui, por isso que o povo fala quem vai a Alcântara e não come do doce, não conheceu a cidade por completa (ENTREVISTADO F).

A culinária maranhense é rica por causa da miscigenação entre várias culturas, como a portuguesa, africana e indígena. Cada uma acrescentou um pouquinho de sua cultura nas preparações que hoje compõem nosso cardápio típico.
Com suas características próprias, a cozinha típica maranhense tornou-se diferente das demais. Assim como o folclore e o artesanato, a gastronomia maranhense sofreu influências indígenas, portuguesas e africanas onde foram adicionados novos condimentos e combinando-os com alimentos que foram trazidos por esses três povos, logo se transformando em uma das culinárias mais apreciadas do país (SILVA, 2010).

O conceito de mediação é próprio do processo do trabalho, e foi por meio dele que se tornou complexa, modificando não só o meio social, mas o próprio homem, pois na medida em que a sociedade foi modificando-se, surgiram novas necessidades dos homens, e consequentemente, novas mediações (ZUIN, 2008).

É importante destacar quando Fagliari (2005) diz que a alimentação é um artifício cultural do cotidiano das pessoas, e está fortemente enraizada em suas vidas. Também se pode observar que para Heck e Beluzzo (1999), a alimentação é uma forma de memória coletiva que resiste ao impacto do tempo com mais força que as demais. Já Franco (2001, p 23) aborda que a alimentação é uma forma de intercâmbio e de comunicação entre as pessoas. Por meio desses autores, é possível observar que a alimentação é uma socialização entre vários grupos, que levam as pessoas à troca do saber cultural, quer seja por turistas, visitante ou entre os próprios povos vizinhos, a comida em torno da mesa nos leva ao conhecimento que se resume a própria cultura de cada povo, e essa troca não cessa, pois na mesma medida que os povos evoluem, a cultura e a gastronomia evoluem também.

\section{Considerações finais}

A partir desse trabalho, pode-se perceber que o "Doce de Espécie" da cidade de Alcântara - MA tem sua relevância, visto que ele é um alimento tradicional e cultural. Este faz o elo entre o passado e o presente de um povo, onde a evolução humana é moldada culturalmente por meio de sua alimentação, neste caso essas práticas culturais se iniciam desde a infância, estabelecendo vínculos alimentares e permanentes por toda a vida. 
A necessidade de estudos sobre o "Doce de Espécie", no seu aspecto histórico-cultural, permeia uma contribuição para atividade turística e para a manutenção de suas tradições culturais. Isso poderá fazer com que essa prática cultural não caía no esquecimento, para tanto também é necessário incentivo por meio do poder público e privado e da comunidade local. Ainda em relação à tradição do "Doce", vimos que por meio dele outros fatores da cultura são preservados na cidade, a população deve valorizá-lo, incentivando e cooperando com pesquisas desse cunho, pois as mesmas também contribuem com esta preservação, divulgação e consolidação, pois se observa que não foram encontrados durante a pesquisa bibliográfica, material bibliográfico relacionado à origem do "Doce de Espécie".

Observou-se pelos relatos dos entrevistados, sobre o "Doce de Espécie", a evidência dos traços ou características luso-açoriano, e que por meio dos escravos ele foi modificado e se tornou o "doce de espécie" de Alcântara - MA. Observou-se ainda, que o "doce" é muito importante na 'Festa do Divino', pois este representa a hospitalidade do povo alcantarense, que durante a festa nas casas dos festeiros aberta para a visita, é considerado como uma forma de recepcionar esses visitantes, pelo simples ato de servir o "Doce de Espécie". Percebeu-se também, que ele serve de fonte de renda para muitos moradores da cidade, e que foi por meio da venda que o "doce" ficou mais conhecido e apreciado por todos que visitam a cidade. E por fim reitera-se que o "Doce de Espécie" é uma iguaria que sustenta de certa forma a cultura alcantarense, por meio de tradições e práticas que envolvem o "doce".

\section{Referências}

ATA 2013. Visit Azores. O Arquipélago. Visit Azores. Sítio Oficial Turismo dos Açores. Disponível em: <http://www.visitazores.com/pt-pt/the-azores/the9-islands/sao-jorge/food-and-drinks>. Acessado em: 23 nov. 2013.
BELLUZZO, Rosa. A valorização da cozinha regional. In: 1a Congresso Brasileiro de Gastronomia e Segurança Alimentar, Brasília - DF. Coletânea de palestras. Brasília, 2004.

BRILLAT-SAVARIN, Anthelme. A Fisiologia do gosto. São Paulo: Companhia das Letras, 2001. 379p.

CASCUDO, Luis Camara, 1898 - História da alimentação no Brasil / Luis da Camara Cascudo. - Belo Horizonte: Ed. Itatiaia; São Paulo: Ed. Da Universidade de São Paulo, 1983.

CORDEIRO, Carlos; MADEIRA, Artur Boavida. A emigração açoriana para o Brasil (1541-1820) uma leitura em torno de interesses e vontades. ARQUIPÉLAGO - HISTÓRIA, 2ª série, VII. 2003.

CUNHA, Manoela Carneiro; ALMEIDA, Mauro. Populações tradicionais e conservação. Programa Nacional da Diversidade Biológica. Seminário de Consulta. Macapá - 21 a 25 de Setembro de 1999. Disponível em: <http://www.socioambiental.org/inst/sem/amazon $\mathrm{ia} / \mathrm{macapa} /$ doc.htm $>$. Acessado em: 22 nov. 2013.

FAGLIARI, Gabriela Scuta. Turismo e alimentação: análises introdutórias. São Paulo: Roca, 2005.

FERREIRA, Marina Vianna; JANKOWSKY, Mayra. Cozinha caiçara: encontro de histórias e ambientes. São Paulo: Editora Terceiro Nome, 2009.

FLADRIN, Jean- Louis; MONTANARI, Massimo. História da alimentação. São Paulo: Estação Liberdade, 1998.

FRANCO, Ariovaldo. De caçador a gourmet: uma história da gastronomia. São Paulo: Editora Senac, 2001. 
FREIXA, Dolores; CHAVES, Guta. Gastronomia no Brasil e no mundo. Rio de Janeiro: Senac Nacional, 2008. 304 p. il.

GINANI, Verônica Cortês. Índice de aceitação de preparações regionais com teor lipídico reduzido. Dissertação de mestrado. Universidade de Brasília, Brasília, DF, 2005.

GONÇALVES, Daniel Evangelho. Síntese sobre a emigração açoriana para o Brasil. Revista Eletrônica Boletim do TEMPO, Ano 5, №23, Rio, 2010.Disponível em: <http://www.tempopresente.org/index.php?option =com_content $\&$ view=article\&id=5454: sintesesobre-a-emigracao-acoriana-parabrasil\&catid=39\&Itemid=127>. Acessado em: 01 dez. 2013.

HALL, Stuart. A identidade cultural na pósmodernidade / Stuart Hall; tradução Tomaz Tadeu da Silva, Guaracira Lopes Louro - 11. Ed. - Rio de Janeiro: DP\&A, 2006.

IPHAN, Convenção da Unesco para a salvaguarda do Patrimônio Cultural Imaterial. Ratificada pelo Brasil em março de 2006. DISPONIVEL EM: $<$ http://portal.iphan.gov.br/portal/montarPaginaS ecao.do? id=10852\& retorno=paginalphan $>$.

Acessado em: 20 nov. 2013.

IPHAN, PORTARIA № 92, DE 5 DE JULHO DE 2012, no Art. $2^{\circ}$, O IPHAN. 2012. DISPONIVEL EM: http://portal.iphan.gov.br/portal. Acessado em: 20 nov. 2013.

LIMA. Zelinda Machado de Castro. Pecados da gula: comeres e beberes das gentes do Maranhão. São Luís, CBPC, 1998.

LOBATO, Fabiana Mendes. Alcântara, passado histórico, presente espacial, futuro turístico. Monografia. Xerox. São Luís. 1992. 85 p. Maranhão uma grande descoberta. Pólo São
Luís; município Alcântara. Disponível em: <www.turismo.ma.gov>. Acessado em: 18 nov. 2013.

MANUAL DO SLOW-FOOD. 2008. Disponível em: $<$ www.slowfood.com/about_us/img_sito/pdf/Com panion08_POR.pdf>. Acessado em: 20 nov. 2013.

MINAYO, M. C. S. Ciência, técnica e arte: o desafio da pesquisa social. In: (Org.). Pesquisa social: teoria, método e criatividade. 18. ed., Petrópolis: Vozes, 1994. p. 9-29.

MONTANARI, Massimo. Le manger comme culture. Bruxelles: Editions de I"Université de Bruxelles, 2010. 184p.

MÜLLER , Silvana Graudenz ; AMARAL, Fabiana Mortimer. A preservação dos saberes e fazeres gastronômicos por meio da articulação entre o Instituto Federal de Educação, Ciência e Tecnologia de Santa Catarina e espaços culturais. Revista Thema.2012, 09 (01). Disponivel em: $<$ http://revistathema.ifsul.edu.br/index.php/thema /article/viewFile/92/56>. Acessado em: 22 nov. 2013.

SANTOS, Carlos Alberto Antunes dos. A alimentação e seu lugar na história: os tempos da memória gustativa. História: Questões \& Debates. Curitiba, n. 42, p. 12, 2005. Editora UFPR.

SIENA, Osmar; MENEZES, Daniel Santos. Gestão do conhecimento em reservas extrativistas. 2007. Disponível em http://www.unifae.br/publicacoes/pdf/Ilseminario/ pdf_praticas/praticas Acessado em: 27 nov. 2013.

SILVA, E. L.; MENEZES, E. M. Metodologia da pesquisa e elaboração de dissertação. 
Florianópolis: Laboratório de Ensino a Distância da UFSC, 2000.

SILVA, Mayara Amorim. Gastronomia: elemento de atração turística em São Luís. Monografia - São Luís, 2010. p. 47.

ZUIN, Luís Fernando Soares. Produção de alimentos tradicionais: extensão rural / Luís Fernando Soares Zuin, Poliana Bruno Zuin. - Aparecida, SP: Idéias \& Letras, 2008. 